Editorial

\title{
Welcome to the inaugural issue of the IRATJ
}

\section{Editorial}

We are proud to present the inaugural issue of the International Robotics and Automation Journal (IRATJ). In this inaugural editorial we outline our vision for the journal and point out its strengths and challenges. In addition to flexible manufacturing systems, robots are crucial to nuclear power plants, space systems, medical devices and micro and nano devices. Moreover, the field of robotics spans several scientific research areas that include neurosciences, biomechanics, hap tics, sensors, mechatronics, control, simulation, optimization, and animation, among others. Robots can reach places and exit in environments that are prohibitive to humans. On the scientific research front, robots are essential for conducting scientific experimentations in extremely harsh conditions like vacuum, radioactive and extremely low or high temperatures applications.

Following the advances of the state of the art in robotics and the increasing demand for research on the design and development of innovative solutions, it is evident that no single journal can cover such a vast scope. Thus the demand for new journals is mandated by the continued progress in this field. The International Robotics and Automation Journal (IRATJ) aspire to furnish the researchers in both academia and industry with the latest advances in the field of robotics and emphasize their practical significance and scientific value. The Journal is intended to provide a wider platform for timely dissemination of knowledge pertinent to the recent research developments in this rapidly growing field. Promoting and facilitating more exchanges and collaborations among worldwide researchers stand as one of the main objectives of this Journal; thus contributing to the future advancements in robotics research. The Journal publishes peer-reviewed, original
Volume I Issue I - 2016

Yehia A Khulief

Department of Mechanical Engineering, King Fahd University of Petroleum \& Minerals, Saudi Arabia

Correspondence: Yehia A Khulief, Department of Mechanical Engineering, King Fahd University of Petroleum \& Minerals, Dhahran 3|26I, Saudi Arabia, Email khulief@kfupm.edu.sa

Received: October 01, 2016 | Published: October 18, 2016

research articles that may include manipulation, automation, sensing, actuation, kinematics and dynamics, micro robotics and other related features. In addition, the Journal provides a venue for scholarly work on integration of experimental and analytical research. We warmly invite you to join its future by submitting manuscripts or reviewing for the journal. As we endeavor to be a high caliber scholarly journal, we are adhering to originality and quality. IRATJ adopts a blind peerreview system with rigorous evaluation criteria closely monitored and managed by an editorial board whose members represent an array of diverse research activities and scholarly achievements.

\section{Acknowledgements}

None.

\section{Conflict of interest}

The author declares no conflict of interest. 